\title{
AN INVESTIGATION OF THE MYGOFLORA IN THE SOIL OF SOME MANGROVE SWAMPS
}

\author{
H. J. SWART \\ (Department of Botany, University of the Witwatersrand, \\ Fohannesburg, South Africa) \\ (received October 15th, 1958)
}

CONTENTS

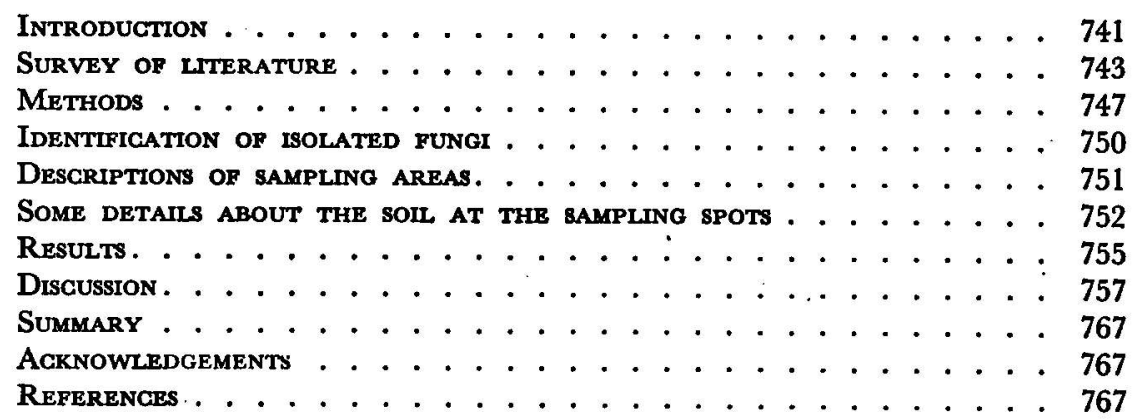

\section{INTRODUCTION}

In recent years the study of the mycoflora of soils has become increasingly popular. There is no doubt that soil fungi are important organisms, but comparatively little is known about their activities. A fair amount of knowledge has been accumulated about soilinhabiting parasitic fungi and the study of antibiotics has increased our knowledge of many saprophytic soil fungi. Nevertheless much more will have to be known about the fungus populations of different soils before we can expect to gain any further insight into the activities of the numerous species present in almost every soil sample.

The objectives of this study are twofold: first, to obtain more factual information about populations of soil fungi; and secondly, to learn something about the factors affecting the distribution of these fungi. With these objectives in mind the author searched for a comparatively small area where one or a few variable factors could be expected to cause considerable differences in the mycoflora of the soil. A preliminary investigation of the soil in a narrow strip of mangrove vegetation on the island of Inhaca (Portuguese East Africa) showed great changes of the fungus population at increasing distances from the channel dividing the swamp. In addition to this promising result several interesting species of fungi were isolated, two of which were found to be new to science (SToLK, 1955). As it seemed that the selected area was ideal for the purposes of the planned investi- 
gation, sampling was continued. Only one series of samples was taken at another location on the same island, where conditions were slightly different. The results of these investigations are presented in the following pages.

A few particulars should be given about the geographic setting and the climate of the island. Inhaca forms part of the barrier between the bay of Lourenço Marques and the Indian ocean, at latitude $26^{\circ}$ south. The island lies in the region of transition from tropical to warm temperate climate. The mean annual range of air temperature is from $18.7^{\circ}$ to $26.9^{\circ} \mathrm{C}$. Rain falls throughout the year but is seldom

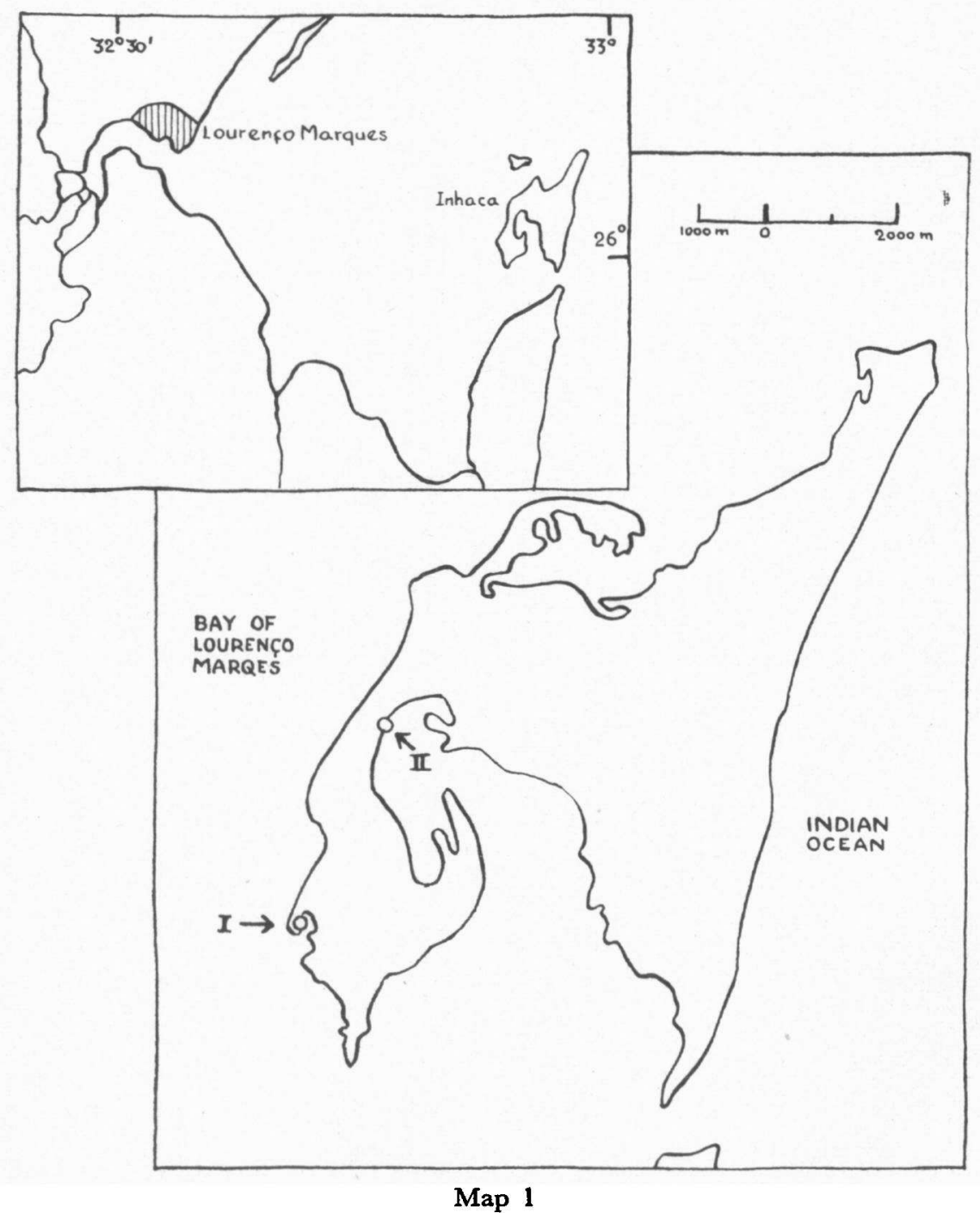


very heavy. The annual total is about $100 \mathrm{~cm}$. Winds are comparatively gentle. Humidity averages $77 \%$. The shape and position of the island and the location of the sampling areas are given on the accompanying map.

\section{SuRvey OF LITERATURE}

Part of the literature that had to be studied in relation to the present investigation, has a direct bearing on some special aspects of the work and will therefore be discussed in the relevant chapters. However, before going into the details of the investigation it may be of some use to give an impression of some of the work that has been done in the field of ecology of microorganisms, particularly as far as the saprophytic soil fungi are concerned.

It is well known that ecological studies can be carried out with lower organisms just as well as with higher plants. The ecology of fungi in relation to certain special substrates is fairly well known. The succession of fungi on dung has been studied for the dung of many animals. WAID (1957) and WEBSTER $(1956,1957)$ have recently studied the succession of fungi taking place on the slowly decomposing remains of certain plants. Such studies make us well aware of the complexities encountered in the study of fungi in soil, as any soil contains a variety of decomposing plant and animal matter.

The study of soil fungi started long ago. Many investigators attempted to find new or otherwise interesting fungi by searching for them in any suitable substratum, including soil. In this way a great number of fungi was isolated from the soil (GiLman, 1957) but in many cases we still know little or nothing about the role these organisms play in the soil and the factors which govern their distribution in different soil types.

The ecological approach to the study of soil fungi is of a more recent date. In the beginning of the century it was still a matter of dispute whether the fungi isolated from soil were really actively growing there, or merely present in a dormant state and activated only by the isolation procedure. This question was finally settled by Waksman. He found living mycelia to be present in soils and thus established the fact that at least some of the organisms isolated from soil must occur there in an active state. Since then the study of the fungus components of soils has steadily progressed and indeed has become very active in recent years.

To facilitate the study of soil fungi, attempts have been made to divide the organisms into several groups, based on their substrate relationships. Thus, GARRETT $(1951,1955,1956)$ has divided the soil fungi into a few large groups. In the first place there are the parasitic organisms. Some of these are obligate parasites, highly dependent on the presence of a suitable host and therefore relatively unimportant in ecological studies. Among the facultative parasites there are such highly specialised organisms like the predaceous fungi which are of equally little importance. Many facultative parasites, however, form an important part of the normal fungus population of soils, and this 
applies particularly to the genus Fusarium. The group of the true saprophytes can be further subdivided. Some of them can only feed on comparatively simple organic compounds whilst they lack the ability to decompose substances like cellulose and lignin. These are called the saprophytic sugar fungi and the most characteristic examples are found among the Zygomycetes. Secondly there are the lignin decomposing fungi, particularly the higher Basidiomycetes, which are of great importance, particularly in forest soils. Garrett lays little emphasis on the cellulose decomposing fungi, which form a somewhat heterogeneous group. Many fungi are able to break down cellulose, but grow much better on simple organic compounds.

In the above classification only a few major groups of soil inhabiting fungi are mentioned. Additional nutritional factors which contribute to the distribution of fungi in soils might be the basis for a more detailed classification (AtKInson and Robinson, 1955). Such a classification would require a much more detailed knowledge of the nutritional requirements and metabolic activities of the soil fungi than we possess at the present moment.

A factor of some importance is the ability of many microorganisms to produce antibiotics. The role of antibiotics in soil has been both underestimated and overestimated. It is usually not possible to extract antibiotics from a nonsterilised soil after inoculation with an antibiotic-producing fungus (Evans and GotTLIEB, 1955). If, however, the same fungus is introduced into a soil containing a substrate for which the organism is known to show a preference, it may be possible to extract the antibiotic from this substrate (WRIGHT, 1956). This antibiotic production will give such a fungus a considerable advantage in the colonisation of its particular substrate, but only those organisms that would normally grow on the same substrate are affected by it. Outside the comparatively small area where the antibiotic-producing organism grows the antibiotic usually cannot be demonstrated, which fact may be due to adsorbtion or to chemical or microbial breakdown (for an example of microbial breakdown see WRIGHT and GROVE, 1957). Garrett's discussion of the significance of antibiotic production is most enlightening (GARRETT, 1956).

At the end of this introductory survey of literature some of the more recent results in the field of ecology of soil fungi may be mentioned. From a compilation of the literature on this subject it becomes apparent that the emphasis is laid on different aspects of the problem, which makes a comparison of the results rather difficult. Some investigators study the mycoflora of soils with a natural vegetation whereas others occupy themselves mainly with cultivated soils. In the first case we will learn something about the natural fungus population, as this population depends not only on the properties of the soil but also on the higher plants present. Both the horizontal and the vertical distribution of soil fungi have been analysed. WARCuP (1952) studied the soil fungi in relation to the soil profile and found that certain fungi showed a definite preference for a certain layer in the profile. Whether or not the fungus population decreases with increasing 
depth is entirely dependent on the properties of the soils studied. BROWN (1958) concluded that there is a general tendency for fungus populations to be poorer in the deeper layers of the soil, if other factors are the same. She also found a correlation between total amount of organic matter and number of mycelia. It is interesting to compare these results with those of McLENNAN and Ducker (1954) who found little change in the fungus population up to a depth of 60 in. and could correlate this with the quantities of organic carbon in their soils. Guillemat and Montégut (1956) considered the depth at which a fungus can grow to be a very important criterion. Only those organisms which regularly occur or at least are able to grow at a depth of $40 \mathrm{~cm}$ should be regarded as proper soil fungi -this of course depends on our definition of the term "soil fungus". The optimum depth was found to be very different for several species that are regularly found in soil. Trichoderma viride was found to have an optimum at $5 \mathrm{~cm}$, Fusarium bulbigenum between 5 and $20 \mathrm{~cm}$, but $F$. solani at $40 \mathrm{~cm}$ ! As far as the horizontal distribution of fungi is concerned, it is usually found that different soils have their own fungus flora (NICHOLLs, 1956). Even a comparatively small change in soil composition may result in the appearance of a different dominant species (Mc LenNan and Ducker, 1957). An investigation of the fungus population of some prairies in Wisconsin-U.S.A. is very interesting in this connection. These prairies ranged from very wet to very dry. There were no essential differences in the fungus flora of the prairies but at different moisture levels of the soils different fungi tended to be more abundant and others were less frequent. If the prairies were compared in a sequence according to the water content of the soil the fungus populations showed only gradual changes. The higher plants followed exactly the same pattern of distribution, with certain species favoured under certain conditions, but no basic differences between the communities occurring on prairies with different amounts of soil moisture (ORPURT and GURTIS, 1957). The fact that the authors found Mucorales to do better in the wetter sites is confirmed in many other investigations. But a preference of Aspergillus for the dry sites is contradicted by the results described further on in this article. One could object to the authors' conclusions about the parallelism in behaviour between lower and higher plants by saying that the first are so much dependent upon the latter that they will automatically follow the same pattern of distribution. It is well known that higher plants have a rhizosphere: a group of microorganisms living in close association with their root system. But these rhizophere organisms form only part of the total amount of microorganisms present in the soil.

The most complete picture of the fungal population of a certain range of soil types will be obtained when both horizontal and vertical distribution of the fungi are studied. This was done by SAKSENA (1955) but the complicated picture obtained made it difficult to reach any general conclusions.

The study of the microflora of cultivated soils can be very helpful 
as it informs us about the influence of the higher plants on the fungal and bacterial population. It is a pity that several investigations of this nature have led to rather contradictory conclusions. ENGHUSEN (1956) in studying the mycoflora of two different soil types under various treatments concluded that the properties of the soil $(\mathrm{pH}$, nutrient levels, humus, moisture) affect the fungus flora more than soil utilisation (forest, cropping) does, unless the change from original forest to cultivation is associated with major changes such as caused by drainage, fertilisation etc. Menon and Williams (1957) came to an entirely different conclusion: In their opinion the crop plant is the decisive factor influencing soil mycofloras and the direct influence of seasonal changes in soil temperature, moisture and $\mathrm{pH}$ may not be appreciable. It is, however, likely that the observed absence of marked seasonal variations is due to the isolation method used by these authors (dilution plate technique). WarguP (1957) in using direct isolation methods as well as plate techniques, found that although many species of fungi have a very short period of activity in the soil, they are always present. Throughout the year fungi show a pronounced periodicity. Seasonal changes were also found by Stevenson and Ghase (1957).

Some investigations of special interest in relation to the work to be discussed in this publication are concerned with the mycoflora of soils along the sea coast and in dunes. Webley, EAstwood and Gimingham (1952) studied the development of the soil microflora in relation to the colonisation of dune sands by higher plants and noticed a positive correlation. They differentiated between a root-surface and a rhizosphere flora which they found to differ from one another, whereas both again were different for the different species of higher plants that colonise these dunes. A similar positive correlation between microflora and surface vegetation was demonstrated by MONTÉGUT (1956). The results of this author showed that Phycomycetes were rare in the coastal area's, probably due to alternating wet and dry conditions. The genus Penicillium was particularly common, whereas Aspergillus was infrequent. Nicot (1956) found Penicillium to be the dominant genus in soil of the Funiperus forest, whereas Aspergillus dominated under Platanus trees. In the dry season, associated with a greater salinity of the soil, Actinomycetes and yeasts were abundant, whereas Trichoderma viride was absent. The work of BROWN (1958) was of a more quantitative nature. This author demonstrated a definite positive correlation between amount of organic matter and number of mycelia.

An interesting investigation of a more physiological nature was carried out by RITCHE (1957), who investigated the influence of temperature on salinity optima for some marine fungi. For two fungi able to grow with or without NaCl, Phoma and Pestalotia, the salinity optimum increased to a higher level with a rise in temperature, whereas in the case of a fungus apparently needing saline conditions, Lulworthia, there were no temperature-salinity relationships and the organism showed a narrow range of temperature tolerance. Investi- 
gations of this nature might be very useful when an explanation is sought for the behaviour of fungi in marine surroundings.

\section{MeThods}

Many methods have been worked out for the study of soil fungi, most of which methods have certain disadvantages. In this respect there is a great difference between fungi and bacteria. In bacterial counts each colony on the plates is derived from a single bacterium and thus a fairly complete picture of the bacterial population of a soil can be obtained by dilution methods. The only limitation lies in the fact that any medium used is selective. With fungi, however, there are many more difficulties. The selectivity of the media can be overcome thanks to the fact that in culture most fungi grow reasonably well on a variety of media. The main problem is that with fungi quantitative and qualitative work can rarely be combined. In methods based on dilution usually a great number will appear of those fungi which sporulate rapidly in soil, and comparatively few fungi which live in the soil in the form of a vegetative mycelium (WARCUP, 1955). For this reason several other methods have been worked out, all based on the principle of bringing a medium in contact with the soil and letting the fungus grow onto it. Here another problem arises. Certain soil fungi grow through the soil as a mycelium and will always be isolated by contact methods. Other fungi, however, do not spread easily and are confined to plant debris and other organic material in the soil. Fungi of this second type sporulate freely and may thus be isolated in great numbers by dilution methods, but they often fail to appear when other methods are used. One of the most successful contact methods is the screened immersion plate technique (ThORNTON, 1952): a thin layer of medium in a flat dish is covered by a screen with a few perforations and the whole is then pressed against the exposed profile of the soil. ThORNTON (1956) compared his method with Warcup's soil plate method (see WARGUP, 1951) which is basically a dilution method. He found an abundance of Rhizoctonia with the former method, and none with the latter. Rhizoctonia could be easily detected by direct microscopic observation of the soil. This fungus is a well known example of an easily spreading sterile mycelium.

Several methods for isolation of soil fungi were tested on a comparative basis by Chesters and Thornton (1956). They came to the conclusion that the results obtained with screened immersion plates showed close agreement with those obtained with more direct methods: immersion tubes and direct inoculation; and that they differed from those obtained by using dilution plates or soil plates. Isolations from screened plates exhibited a wider range and variety of species than those obtained by any other methods, particularly for species of Mortierella and dematiaceous fungi, and they also provided a quantitative measure of the relative distribution of species.

All these methods for studying soil fungi are more or less indirect. More direct methods for observing fungi as they are present in soil 
have been worked out, one of the latest being described by Miss Brown (1958). A slide is covered with an adhesive and then pressed against the soil surface. After staining, the thin layer of soil plus organisms is observed directly under a microscope with an $8 \mathrm{~mm}$ metallurgical objective. Such methods give an impression of how fungi live and spread in soil; they can be used for quantitative work on a comparative basis by comparing the amounts of mycelium visible on the slides. Identification of the organisms observed is usually not possible.

MaLennan and Ducker (1954) compared the results of such a direct method with those obtained by a dilution technique. They found a good correlation and concluded that the dilution method is not as unreliable as is often stated.

One fact about the majority of isolation techniques should be clearly stated. Hardly any method makes it possible to differentiate between fungi that are actively growing in the soil and others that are present in a dormant state. Only direct observation is entirely reliable in distinguishing between these two groups, but this method suffers from serious limitations in other respects. The study of seasonal changes is thus made very difficult and can never give reliable results if any dilution or direct inoculation method is used. This appears clearly from the results of the study by WARGuP (1957) mentioned earlier. If, as in the present investigation, the influence of seasonal changes on the results should be limited as much as possible, most of the methods mentioned will have this effect automatically.

When a suitable method had to be chosen for studying the soil fungi in a mangrove swamp and the surrounding area, several points had to be considered. It was intended to obtain qualitative information in the first place and secondly, as far as possible, some impression of the quantities of the different fungi. A direct inoculation method (described on p. 749) seemed to be the best. The decision to use such a method was taken when the work was started in 1953 and its usefulness was later underlined by the comparative study of Chesters and Thornton cited above. The two other methods found to be suitable by these authors could not be used under the present circumstances as the regular inundation of the swamp made it impossible to cut soil profiles and to bury anything in the soil without it becoming subsequently disturbed. The loose sand around the swamp presented similar difficulties.

The choice of a suitable isolation medium was another important point. For the first attempts the same medium was chosen as recommended by WARCUP (1951) as it is suitable for a great variety of fungi. This medium (Czapek-Dox agar + yeast extract) soon presented a major difficulty as it turned out to be very suitable for yeasts and bacteria as well. When a tomato-decoction agar was tried it was found that even more different fungi could be isolated, whereas the growth of bacteria and yeasts was considerably slowed down. For all later analyses both media have been used, each in two modifications as described below. 
The method of sampling has a great influence on the final results of the investigations. Rose and MiLler (1954) took samples in meadows in New Zealand and found that for each meadow they had to mix 32 samples in order to obtain consistent results. Luckily in and around a mangrove swamp both soil and vegetation are very homogeneous. For this reason the author mixed only four samples at each sampling point. Although this may not have been sufficient for accurate counts, the qualitative results of the different series of samples showed the same tendencies and therefore the sampling method adopted was estimated to be sufficient for the purpose. The samples were kept in sterile metal containers and these were sealed with Sellotape. This made it possible to store the samples until they could be studied in the laboratory, without any appreciable change in moisture content taking place.

Samples were taken to a depth of not more than $5 \mathrm{~cm}$ and included some of the surface soil, so that possibly several fungi were isolated that did not belong to the actual soil population. However, several investigations have shown that, when present on the surface of a soil, spores of fungi that do not belong to the microflora of that soil, do not survive long and will never develop (PARK, 1957, a, b). In several cases spores lying on the surface of the soil were found to become rapidly decomposed (PARK, 1955). An experiment was done to compare the results from a sample taken at the surface and one taken at greater depth, with those from a mixed sample. They show that there is no surface population of fungi significantly different from that in the underlying layer. A more detailed discussion of this experiment is included in the chapter dealing with results in general.

It is well known that fungus populations of soils vary with depth (Warcup, 1951; Guillemat and Montégut, 1956; Brown, 1958). In a mangrove swamp soil conditions are definitely anaerobic and, as most fungi have difficulties in growing under such conditions, it was decided to sample only the superficial layers of the soil and study the horizontal rather than the vertical changes in fungus population.

After this general discussion of the methods it seems advisable to give a detailed description of the procedures used in sampling and analysing.

Samples were collected in small metal containers. The sample included soil to a depth of about $5 \mathrm{~cm}$. From each sampling point four samples were taken, mixed, and the container was sealed with Sellotape on the spot.

Laboratory analysis: The samples were analysed for their fungus content by inoculating suitable media with small soil particles. Each medium was inoculated with 100 particles (5 petridishes with 20 particles each). For most series of samples four different media were used. After having been inoculated the dishes were kept in an incubator at $25^{\circ} \mathrm{G}$ for 7 days. Final analysis was done by inspecting each dish under low power (total magnification about $100 \times$.) Many fungi were then already fruiting and could be identified straight away. All sterile mycelia were isolated for subsequent identification. 
As mentioned above the first medium tried was a modification of Czapek-Dox agar, prepared according to the following description:

\begin{tabular}{|c|c|c|}
\hline Solution & $\begin{array}{l}\text { water } \\
\mathrm{NaNO}_{2} \\
\mathrm{KH}_{2} \mathrm{PO}_{4} \\
\mathrm{MgSO}_{4} \cdot 7 \mathrm{H}_{2} \mathrm{O} \\
\mathrm{KGl} \\
\mathrm{FeSO} \\
\text { Agar }\end{array}$ & $\begin{array}{cc}700 & \mathrm{~m} \\
3.0 & \mathrm{~g} \\
1.0 & \mathrm{~g} \\
0.5 & 8 \\
0.5 & 8 \\
0.01 & 8 \\
20 . & 8\end{array}$ \\
\hline
\end{tabular}

Both solutions were sterilised separately at 1 atm. for 20 mins. In case a second sterilisation is necessary after mixing, it should be done at $100^{\circ} \mathrm{C}$ for $1 \mathrm{hr}$.

Since some fungi have a preference for media with a higher osmotic value, a concentrated version of this medium was used as well. It. was made by using $75 \mathrm{~g}$ of the sugars instead of $15 \mathrm{~g}$.

The second medium was made from a tomato decoction: $300 \mathrm{ml}$ decoction are prepared from 400 to $500 \mathrm{~g}$ of tomatoes. A second solution is made from $700 \mathrm{ml} \mathrm{H}_{2} \mathrm{O}$ and $20 \mathrm{~g}$ agar. Both solutions are sterilised separately under pressure and subsequently mixed. The concentrated version of this medium was made by adding $30 \mathrm{~g} \mathrm{NaCl}$ to the second solution.

Whenever one or both these media were used, plating out as described above was done on both the original and the concentrated version, giving a total of 200 or 400 particles inoculated per sample.

\section{IDENTIFICATION OF ISOLATED FUNGI}

For any qualitative work on a fungus population it is advisable to find the specific name of all isolates. In practice, however, this procedure often proves to be a rather difficult one. Comparatively few monographs are available and even when a monograph exists, identification of a species may be difficult and time-consuming.

In the present investigation the number of fungal colonies occurring on the plates was high. As no facilities for maintaining large numbers of fungal cultures over an extended period and no assistance for the identification of isolates were obtainable, it was decided not to attempt identifications of species, except in the case of the genera Aspergillus and Penicillium. These two large genera are very common and excellent monographs make identification comparatively easy. Moreover a great deal is known about the physiology of the different species and thus the identification of species in these genera may provide us with valuable information concerning the interrelations between soil properties and the physiological activities of the fungus population. It is realised that a detailed study of some other genera, particularly a large and varied genus like Fusarium, may give very interesting information and the author hopes to continue his work on the mangrove fungi with studies of this kind.

Literature used for identification purposes only is not listed in the list of references, except when it is mentioned in the text. 


\section{DESCRIPTION OF SAMPLING AREA's}

The samples came from two different localities, which will be described in detail. Additional information on the vegetation of the island can be found in a recent book on the natural history of Inhaca (MACNAE and KALK, 1958).

Area I (fig. 1): A narrow strip of mangrove vegetation near Ponta Rasa on the southwestern part of the island. The swamp is split longitudinally by a channel through which seawater streams in and out, according to the changes of the tide. Along this channel many specimens of Rhizophora mucronata are growing (fig. 1, zone A) whilst the remainder of the swamp contains a mixture of this species, Bruguiera cylindrica and Ceriops tagal (fig. 1, zone B); Avicennia marina is entirely absent. In this area many Uca crabs and some Sesarma crabs can be found. The soil is fairly soft, black in colour, and has a high moisture content. A faint smell of $\mathrm{H}_{2} \mathrm{~S}$ can be noticed. Directly outside the actual swamp the soil is rather sandy and the vegetation consists of herbaceous halophytes (fig. 1, zone C). The dominant species here is Sesuvium portulalastrum mixed with some. Chenolea diffusa. Further away from the swamp the first isolated plants of Sporobolus virginicus can be found. This species gradually forms a dense cover (fig. 1, zone D) and then other grasses and the first shrubs occur (fig. 1, zone E).

Area II (fig. 2): A strip of Avicennia swamp along the lagoon that cuts right into the centre of the island. The soil here is sandy. At low tide this area, like the greater part of the lagoon, is completely dry. Outside the strip of Avicennia marina only a few seedlings of this

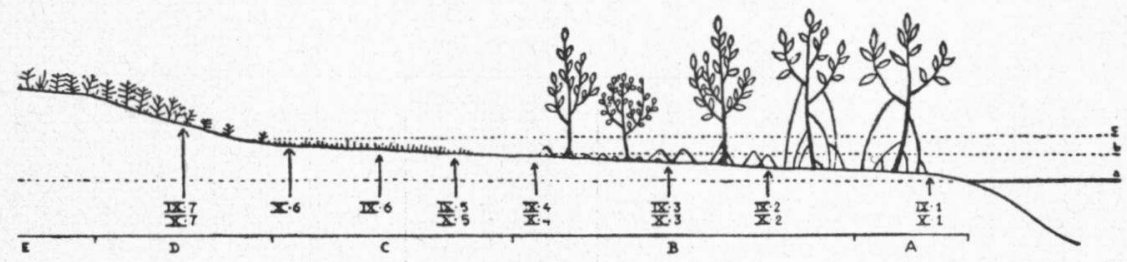

Fig. 1. Diagrammatic section through sampling area I, situated near Ponta Rasa Dimensions based on estimations.

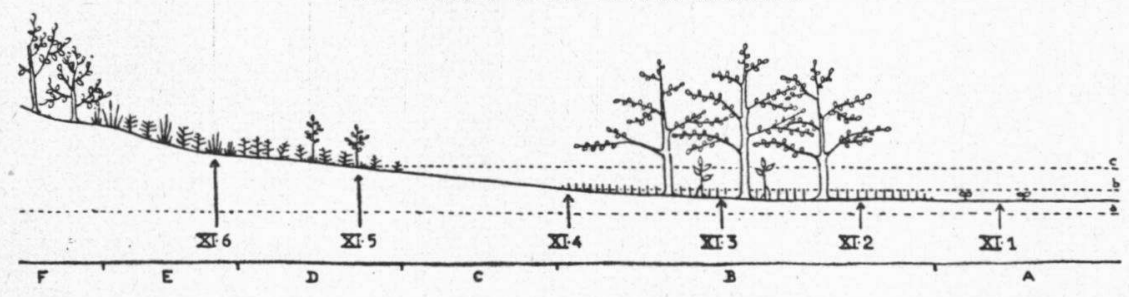

Fig. 2. Diagrammatic section through sampling area II, situated on the Western part of the lagoon. Dimensions based on estimations.

Figs, 1 and 2. a) average low tide level;

b) average high tide level;

c) water level at highest spring tides;

for further explanation see text. 
tree can be found and these seem to die soon (fig. 2, zone A). Among the Avicennia trees some Rhizophora seedlings occur (fig. 2, zone B). The zone outside the swamp, where one would expect herbaceous halophytes to be present, is completely bare as it is used as a path by the native population of the island (fig. 2, zone C). Beyond this path we again find Sporobolus and some young Avicennia trees (fig. 2, zone D). Further on various grasses appear and the vegetation gradually changes into the mixed bush that is characteristic for the inland vegetation of the island (fig. 2, zone $\mathrm{E}$ ).

In each area samples were taken along a straight line. The points at which these samples were collected were chosen in relation to the changes in soil type and vegetation as indicated in figs. 1 and 2.

\section{SOME DETAILS about THE SOIL at THE SAMPLING SPOTS}

As the physical and chemical properties of the soil have a profound influence on the vegetation, including the microflora, it seems important that some of these properties should be known. Valuable information might be obtained if some correlation between soil properties and microflora could be demonstrated. For this reason several variable factors were investigated: $a$ ) moisture content and soil temperatures, $b$ ) nutrient level: carbon and nitrogen, $c$ ) salinity.

a) The moisture content of all samples was measured as soon as the sealed containers were opened in the laboratory. The soil was dried at a temperature of $110^{\circ} \mathrm{C}$ for $24 \mathrm{hrs}$; any longer drying did not result in further loss of weight. The results are given in table $I$.

TABLE I

Water content of soil samples, given as milligrams of water per 1 gram dry weight of soil. For details on series XII see next chapter

\begin{tabular}{l|c|c|c|c|c|c|c}
\hline \hline Series IX $\mathrm{n}^{\circ}$ & 1 & 2 & 3 & 4 & 5 & 6 & 7 \\
Water content & 502 & 332 & 249 & 103 & 77 & 48 & 6 \\
Series X n & 1 & 2 & 3 & 4 & 5 & 6 & 7 \\
Water content & 621 & 275 & 318 & 57 & 9 & 6 & 1.5 \\
Series XI n & 1 & 2 & 3 & 4 & 5 & 6 & \\
Water content & 315 & 348 & 324 & 248 & 104 & 8 & \\
Series XII n & 1 & 2 & 3 & 4 & 5 & 6 & \\
Water content & 287 & 250 & 266 & 65 & 73 & 63 &
\end{tabular}

Some of these figures need further explanation. The pronounced difference between series IX and $X$ as far as spots 5 and 6 are concerned, may be explained by the fact that the highest spring tides occasionally cover these spots. The same applies to spot 5 from series XI-here such a high tide occurred on the day previous to the sampling. The relatively high moisture content of samples 4,5 and 6 in series XII as compared with the corresponding spot 7 from series IX and $\mathrm{X}$, can be explained by the fact that samples in series XII were taken in the afternoon after a rainy morning. 
One other physical factor has been measured. The temperature of the soil can be important in relation to evaporation and by its direct influence on the growth of fungi. Temperatures were measured at 1 inch depth at 4 different spots at 3 p.m. The highest temperatures seem to be the most important as they surpass the optimum temperatures of many fungi. The results are shown in table II.

TABLE II

Soil-temperature measurements in ${ }^{\circ} \mathrm{C}$, taken on a dry sunny day, one day before collecting sample XII. The spots are indicated by the numbers used for series IX as this was most convenient

\begin{tabular}{c|c|c|c|c}
\hline \hline \multicolumn{2}{c|}{ Air temperature: 26} & \multicolumn{3}{|c}{ Surface water in swamp: 26 } \\
\hline spots & IX, 3 & IX, 6 & IX, 7 & in shrubbery beyond \\
temperature & 25 & 31 & 31.5 & $\begin{array}{c}\text { sampling area } \\
27\end{array}$
\end{tabular}

It is shown that soil temperature in the swamp varies even less than air temperature, whereas in the more open vegetation soil temperatures are reached which are definitely inhibitory to fungi with a comparatively low temperature optimum, like many of the Zygomycetes. These measurements were taken in September and it can be safely assumed that in December and January the temperatures will reach higher levels, particularly in the more open vegetation.

b) For the chemical analysis of the soil three samples were collected at spots corresponding to series IX no. 3, 6 and 7, as these spots are characteristic for the three main zones of the vegetation. The analysis of these samples for carbon and nitrogen was very kindly undertaken by the laboratories of African Explosives and Chemical Industries in Modderfontein. Before handing over the samples the $\mathrm{pH}$ was measured by means of a glass electrode, using a suspension of $10 \mathrm{~g}$ soil in $20 \mathrm{ml}$ destilled water. The values found are:

spot IX, 3: 7.3; spot IX, 6: 8.9; spot IX, 7: 8.8.

The resuits of the chemical analysis are shown in table III. It will be noticed that the moisture content does not correspond to the previous findings. This may be explained by the fact that the samples for chemical analysis were kept in corked containers, whereas the samples from which the author took his measurements were carefully sealed. For this reason the results on a dry basis should be regarded as more reliable than those on a wet basis.

It is interesting to study the results obtained for Nitrogen in its different forms. When comparing the values for total $\mathrm{N}$ with those for inorganic $\mathbf{N}$ (Ammonium + Nitrate) it becomes clear that at spot IX, 3 total $\mathrm{N}$ is much higher than at other spots, but this is not the case for inorganic $\mathrm{N}$. It can be safely assumed that the soil at spot IX, 3 contains more $\mathbf{N}$ in organic form than at the other spots. Inorganic $\mathrm{N}$ becomes more important in the sandy soil of spot IX, 7 . The values for Ammonium- $N$ are far more variable than those for Nitrate N. 
TABLE III

Results of analysis of soil for $\mathrm{C}$ and $\mathrm{N}$ as given by the laboratories of A.E. \& C.I. All figures in p.p.m. except when otherwise indicated. Where the results of more than one measurement are given the mean values are printed in bold type

\begin{tabular}{|c|c|c|c|}
\hline Test & IX, 3 & IX, 6 & IX, 7 \\
\hline $\begin{array}{l}\text { Total N }(\%) \\
\text { Carbon } \quad(\%)\end{array}$ & $\begin{array}{l}0.05 \\
0.9\end{array}$ & $\begin{array}{l}0.03 \\
0.3\end{array}$ & $\begin{array}{l}0.03 \\
0.5\end{array}$ \\
\hline Moisture (\%) & $18.5,19.3-18.9$ & $10.6,10.4-10.5$ & $6.9,6.3-6.6$ \\
\hline $\left.\begin{array}{c}\underset{\text { Ammonium } N}{N} \\
\text { as }\end{array}\right\} \begin{array}{l}\text { on wet basis } \\
\text { on dry basis }\end{array}$ & $\begin{array}{r}9 \cdot 10 \cdot 9-9 \\
11 \cdot 12 \cdot 11-11\end{array}$ & $\begin{array}{l}2 \cdot 4 \cdot 4-3 \\
3 \cdot 5 \cdot 5-4\end{array}$ & $\begin{array}{l}14 \cdot 11-13 \\
16 \cdot 12-14\end{array}$ \\
\hline$\underset{\text { Nitrate } N}{\text { as } N} \quad\left\{\begin{array}{l}\text { on wet basis } \\
\text { on dry basis }\end{array}\right.$ & $\begin{array}{l}12 \cdot 13 \cdot 10 \cdot 19-14 \\
14 \cdot 16 \cdot 13 \cdot 23-17\end{array}$ & $\begin{array}{l}12 \cdot 13 \cdot 9-11 \\
14 \cdot 14 \cdot 10-13\end{array}$ & $\begin{array}{l}17 \cdot 19 \cdot 30 \cdot 22-22 \\
19 \cdot 20 \cdot 32 \cdot 23-24\end{array}$ \\
\hline $\left.\begin{array}{c}\text { Nitrate } \mathrm{N} \\
\text { by difference }\end{array}\right\} \begin{array}{l}\text { on wet basis } \\
\text { on dry basis }\end{array}$ & $\begin{array}{l}\text { mean: } 5 \\
\text { mean: } 6\end{array}$ & $\begin{array}{l}\text { mean: } 8 \\
\text { mean: } 9\end{array}$ & $\begin{array}{l}\text { mean: } 9 \\
\text { mean: } 10\end{array}$ \\
\hline
\end{tabular}

The values for total carbon are high in the mangrove mud (IX, 3), low in the sand of the halophyte zone (IX,6) and fairly high in the grassland soil (IX, 7). As there seems to be a decrease in organic $\mathrm{N}$ from IX, 6 to IX, 7, the increase in total $\mathrm{C}$ must be due mainly to the carbohydrates.

c) The salinity of the soil is another variable factor of importance Sodium chloride could be active in two ways: firstly by increasing the osmotic value of the liquid fraction of the soil and secondly because the chloride ion becomes toxic when it is present in too high a concentration. The salinity measurements were not carried out by A.E. \& C.I., but fortunately an arrangement could be made with the Chemistry Department of the Witwatersrand University to have this analysis done by one of the advanced students. Two sets of samples were investigated. The samples $X, 3, X, 5$ and $X, 7$ were about $2 \frac{1}{2}$ years old when analysed. A special set of fresh samples was later collected at spots corresponding to IX, 3, IX, 6 and IX, 7. The results of the analysis are given in table IIIa.

TABLE IIIa

Cl-content of mangrove and surrounding soils on dry basis

\begin{tabular}{|c|c|c|c|c|}
\hline old & $\begin{array}{c}\text { sample } \mathrm{n}^{\circ} \\
\% \mathrm{Cl}\end{array}$ & $\begin{array}{l}X, 3 \\
1.607\end{array}$ & $\begin{array}{l}X, 5 \\
0.590\end{array}$ & $\begin{array}{l}\mathrm{X}, 7 \\
0.087\end{array}$ \\
\hline fresh & $\begin{array}{c}\text { sample } \mathbf{n}^{\circ} \\
\% \mathrm{Cl}\end{array}$ & $\begin{array}{c}(\mathrm{IX}, 3) \\
0.76\end{array}$ & $\begin{array}{c}(\mathrm{IX}, 5) \\
0.43\end{array}$ & $\begin{array}{c}(\text { IX, } 7) \\
0.69\end{array}$ \\
\hline
\end{tabular}

Note: The second set of figures was received after the manuscript had been handed to the printer. At the present moment no explanation can be given for the fact that these figures differ so much from those obtained from the old samples. Only the first set of figures agrees with the author's expectations as based on local conditions and type of vegetation. 
In interpreting these results it should be kept in mind that the moisture content of the mangrove soil (lst sample) is rather high whereas that of the halophyte zone (2nd sample) is much lower and far more variable. The same applies to the grassland (3rd sample) but there the $\% \mathrm{Cl}$ is very much lower. It can be expected therefore that the highest osmotic pressures in the soil will occur in the halophyte zone from time to time.

\section{Results}

The results of the preliminary investigation will not be given in full, as the way of sampling was inadequate, but some details may be mentioned. Apart from two new Ascomycetes, later described by Miss Stolk (1955), an interesting ascosporous species of Aspergillus was found three times in the actual mangrove soil. The morphology and systematic position of this organism are discussed in a separate article to be published in a different periodical. The organism definitely belongs in the Aspergillus glaucus group. As can be seen from the results of further investigations, members of this group are not common and are restricted to the black mud of the mangrove swamp. Another feature shown by this trial analysis, as well as by the results of subsequent samplings, is the occurrence of a great variety of species in the mangrove soil, whereas the total number of colonies is often highest in the grassland. This greater number of fungal isolates is caused by a pronounced numerical increase of a few genera like Fusarium and sometimes Trichoderma, and a decrease in number of bacteria and yeasts.

The series of samples to be discussed in detail are numbered IX to XII. Series IX was sampled in area I on the 7th of July 1954 (midwinter). Series $\mathrm{X}$ was sampled in the same area but in a different season: on the 9th of January 1956 (midsummer). A comparison of these samples shows the same general trends in both. In these and other series only such general aspects can be discussed. It is well known that fungus populations vary with the seasons, but, as the author was unable to visit the island regularly, he could not study seasonal variations.

Series XI is the only one collected in area II. This area differs from area I mainly in the mangrove zone where both vegetation and soil are different.

Series XII was again collected in area I. This series was sampled in a special way in order to show that including the surface layer of the soil in the samples had not distorted the overall picture of the soil mycoflora obtained by the analysis of the previous series. To this purpose the six samples of this series were collected in the following way:

XII, 1, 2 and 3, collected at the same spot as IX, 3 .

1: surface layer only - less than $\frac{1}{2} \mathrm{~cm}$ deep;

2: deeper layer only $- \pm 2 \mathrm{~cm}$ deep;

3: mixed sample, from surface up to $2 \mathrm{~cm}$. 
XII, 4, 5 and 6, collected at the same spot as IX, 7.

$$
\begin{aligned}
& \text { 4: surface layer; } \\
& \text { 5: deeper layer; } \\
& \text { 6: mixed sample. }
\end{aligned}
$$

The results of the analysis as given in table IV will be discussed in detail in the next section, but a few remarks are made here. The results of sample XII, 6 are not as reliable as those of the other samples. At the moment, at which plating out was started, it was discovered that some of the Czapek-Dox dishes, prepared in advance, had become infected. Only 150 particles instead of 200 were put on this medium; the result shown in table IV is adjusted by multiplication. An interesting feature is that the results of the mixed samples (3 and 6) are not always intermediate between those of surface and deeper samples. This shows the variability of results of this type of work and demonstrates that only general trends are sufficiently reliable to be discussed.

The results obtained from series IX and $X$ are given in tables $V$ and VI respectively. When series IX was analysed the second medium (tomato decoction agar) had not yet been introduced. The details of these results will be discussed in the next section. For the position of the sampling spots fig. 1 should be consulted.

The results obtained from series XI are given in table VII. Although the details will be discussed in the next section a few explanatory remarks should be made here. In sample 6 there was such an abundance of Absidia that an exact account of the other fungi present could not be obtained. Below the Absidia mycelium many colonies of certain species of Aspergillus could be recognised. Isolation and identification of species of Penicillium was not possible. The number of imperfect fungi is probably higher than appears from table VII. For the position of the sampling spots fig. 2 should be consulted:

A short explanation should be given of the way in which tables IV to VII are composed. The "perfect" fungi are listed first, with the exception of the very common genera Aspergillus and Penicillium which are listed separately. These common genera are relatively well known, both systematically and physiologically. In the genus Aspergillus the different groups are fairly homogeneous so that in general an identification beyond the group seems unnecessary for the purposes of this study. The same applies to the genus Penicillium, although to a lesser extent. From the Imperfect fungi two genera were singled out: Fusarium and Trichoderma, as they are amongst the most common fungi in almost any soil. The remaining genera were arranged according to the three "orders" Sphaeropsidales, Melanconiales and Moniliales, and the latter order was split in hyaline and dark forms.

A few words should be said about the identification of some of the Ascomycetes. In the case of $\mathcal{N}$ eocosmospora the species was $\mathcal{N}$. africana von Arx in all cases. The isolate listed as Melanospora is of doubtful systematic status. It belongs to the Melanosporaceae, is heterothallic, 
and produces perithecia that are slightly different from those of Melanospora and Chaetomium. Further studies will have to be made to elucidate the exact systematic position of this organism. The fungus identified as probably Xylaria produces Xylaria-like fruiting structures in pure culture. Conidia have been found on the pink tips of these otherwise black structures, but perithecia have not been observed. The author has not yet found the fruiting bodies of Xylaria anywhere on the isiand. In the genus Aspergillus only a few perfect species were isolated: some closely related members of the $A$. glaucus group and A. nidulans. Only one perfect species of Penicillium was encountered: P. spiculisporum.

\section{Discussion}

The last series of samples, series XII, has to be discussed first as the results obtained from it are of importance for the interpretation of all previous work. The series was sampled in order to show that including the surface layer of the soil in the samples had not distorted the overall picture of the soil mycoflora as obtained by the analysis of previous series. Theoretically it is possible that spores from the atmosphere come to rest on the soil surface and give rise to colonies when the samples are plated out. However, these colonies would form a small minority among the cultures arising from spores or mycelium present in the subsurface part of each sample. In addition to this the work of PARK (1955, 1957) indicates that spores from fungi, that are not soil organisms, have little chance to survive on (and in) soil and, when germinating, are unable to compete with true soil inhabitants. On the plates a number of fungal and bacterial colonies arise from each soil particle and thus competition plays a role here as well as in the soil.

From an examination of table IV it becomes clear that a pronounced difference between surface soil and subsurface soil occurs only in the second part of the series-samples 4 and 5-and only as far as the genus Penicillium is concerned. A comparison with the results of samples IX, 7 (table V) and X, 7 (table VI), collected more or less at the same spot, shows that this greater number of Penicillia in the surface layer did not influence the results of the analysis of those two samples. Apart from Penicillium, differences between the samples in series XII are small and mainly of a quantitative nature. The variability of the results of this series, particularly the fact that the mixed sample is sometimes not intermediate between the two other samples from the same spot, indicates that, in general, no conclusions should be based on the occurrence of fungi that are present in small numbers only.

Some other features, shown in table IV, confirm the results of previous series and will be mentioned when those series are discussed. One point, however, can be mentioned here, as all tables show it. The total number of fungal colonies on the tomato decoction agar is always higher than on the Czapek-Dox medium. This is due partly to the fact that tomato agar is not very suitable for the development 
TABLE TV:RESULTS OF ANALYSIS OF SAMPLES FROM SERIES XII. BOTH MEDIA WERE USED AND THE FUNGI ISOLATED ON EACH ARE LISTED SEPARATELY. $\quad C_{z} \cdot D=\operatorname{modified} C_{\text {zapek }}$ Dox agar

\begin{tabular}{|c|c|c|c|c|c|c|c|c|c|c|c|c|}
\hline \multicolumn{2}{|c|}{ SAMPLE n: } & \multicolumn{2}{|c|}{1} & \multicolumn{2}{|l|}{2} & \multicolumn{2}{|l|}{3} & \multicolumn{2}{|l|}{4} & 5 & \multicolumn{2}{|c|}{6} \\
\hline MEDIUM & & $C_{2} D$ & $T$ & G.D & & C.D. & & $C_{2} .0$ & & 2.D $\mid T$ & $G_{2} D$ & $T$ \\
\hline PHYCOMYCETES: & $\begin{array}{l}\text { Absidia } \\
\text { Rhizopus }\end{array}$ & & : & & & & & & & & & \\
\hline ASCOMYCETES: & $\begin{array}{l}\text { Chaetomium } \\
\text { PMelanosporo } \\
\text { Neocospospora } \\
\text { Sordario } \\
\text { unidentified }\end{array}$ & 1 & & 1 & & 1 & & & & & & 4 \\
\hline $\begin{array}{c}\text { Aspergillus } \\
\text { (groups only) }\end{array}$ & 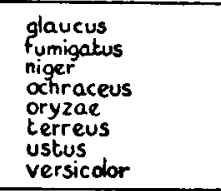 & $\begin{array}{l}16 \\
2 \\
1 \\
3\end{array}$ & 21 & $\begin{array}{l}1 \\
1 \\
2 \\
1 \\
3\end{array}$ & 7 & & $\begin{array}{c}8^{2} \\
\frac{1}{3} \\
3 \\
1\end{array}$ & $\begin{array}{l}4 \\
2 \\
1\end{array}$ & $\begin{array}{l}2 \\
3 \\
1\end{array}$ & $\begin{array}{ll}2 & 2 \\
2 \\
3 \\
3\end{array}$ & I & 4 \\
\hline $\begin{array}{l}\text { Penicillium } \\
\text { (groups sonly, } \\
\text { in systematical order) }\end{array}$ & 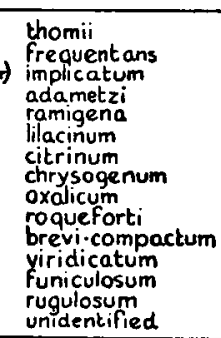 & $\begin{array}{l}3 \\
3 \\
1 \\
5 \\
5\end{array}$ & $\begin{array}{l}2 \\
24 \\
2\end{array}$ & 2 & $\begin{array}{c}10 \\
1 \\
2 \\
22\end{array}$ & $\begin{array}{l}1 \\
7 \\
1 \\
1 \\
1\end{array}$ & $\begin{array}{l}1 \\
\vdots \\
3 \\
1 \\
1 \\
5 \\
5 \\
5\end{array}$ & 4 & $\begin{array}{l}2 \\
11 \\
2 \\
1 \\
3\end{array}$ & 1 & ' & $\begin{array}{l}3 \\
1 \\
3 \\
1 \\
1\end{array}$ \\
\hline BASIDIOMYCETES & & & & & & & & & & & & \\
\hline IMPERFECTI & $\begin{array}{l}\text { Fusarium spp. } \\
\text { Trichoderma }\end{array}$ & $\begin{array}{l}21 \\
5 \\
\end{array}$ & $\begin{array}{c}25 \\
5\end{array}$ & $\frac{11}{3}$ & 5 & $\begin{array}{l}3 \\
2\end{array}$ & 6 & $\begin{array}{l}92 \\
13\end{array}$ & $\begin{array}{l}102 \\
16\end{array}$ & \begin{tabular}{l|l}
25 & 3 \\
163 &
\end{tabular} & $\begin{array}{l}3 \\
9 \\
9\end{array}$ & $\int_{>14}^{159}$ \\
\hline $\begin{array}{r}\text { IMPERFECTI } \\
\text { generall } \\
\text { Sphaer: }\end{array}$ & $\begin{array}{l}\text { Maplosporella } \\
\text { phoma } \\
\text { Peyronellaea }\end{array}$ & 2 & & & & 1 & & & & 1 & & \\
\hline Melanc. & Pestalotia & 83 & 168 & 38 & 1110 & 61 & 25 & 55 & 121 & 112 & \begin{tabular}{l|l}
9 & 8 \\
\end{tabular} & 45 \\
\hline $\begin{array}{c}\text { Monil. } \\
\text { hydline }\end{array}$ & $\begin{array}{l}\text { Cyylindrocladium } \\
\text { P.eecilomyces }\end{array}$ & & 4 & & & & & & & & & \\
\hline $\begin{array}{c}\text { Monil. } \\
\text { pigmented }\end{array}$ & $\begin{array}{l}\text { Alternaria } \\
\text { Beterania } \\
\text { Cladosporium } \\
\text { Curvularia } \\
\text { Haplographium } \\
\text { Helminthosporium } \\
\text { Nigrosposa } \\
\text { Papplaria } \\
\text { Periconia } \\
\text { Stachybotrys } \\
\end{array}$ & $\begin{array}{l}1 \\
17\end{array}$ & $\begin{array}{l}1 \\
27 \\
1\end{array}$ & $\begin{array}{l}5 \\
5 \\
3 \\
1\end{array}$ & 8 & $\begin{array}{l}1 \\
1 \\
2\end{array}$ & 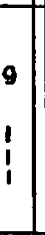 & $\mid \begin{array}{c}1 \\
15 \\
5\end{array}$ & \begin{tabular}{|l|}
12 \\
1 \\
44 \\
79 \\
13 \\
6
\end{tabular} & $\begin{array}{l}2 \\
2 \\
2\end{array}$ & $\begin{array}{l}10 \\
2\end{array}$ & $\begin{array}{l}2 \\
6 \\
90 \\
6 \\
9\end{array}$ \\
\hline $\begin{array}{l}\text { TOTAL- different gene } \\
\text { TOTAL- colonies }\end{array}$ & era (groups) & \begin{tabular}{|l|}
18 \\
172 \\
\end{tabular} & 19 & \begin{tabular}{|l|}
16 \\
90
\end{tabular} & $\begin{array}{c}14 \\
196\end{array}$ & \begin{tabular}{|l|}
20 \\
132
\end{tabular} & 22 & \begin{tabular}{|l|}
13 \\
196 \\
\end{tabular} & $\begin{array}{l}19 \\
4,8\end{array}$ & & \begin{tabular}{c|c}
3 & 7 \\
29 & 128
\end{tabular} & \begin{tabular}{|l}
16 \\
349
\end{tabular} \\
\hline $\begin{array}{l}\text { STERILE MYCELIA } \\
\text { UNIDENTIFIED }\end{array}$ & & 2 & & 1 & & & $\frac{1}{2}$ & 2 & 1 & & $>5$ & \\
\hline
\end{tabular}


of bacteria and yeasts, thus giving the fungi a better chance to develop. This leads not only to an increase in the number of colonies, but also to the isolation of a greater number of genera and species. Secondly, the author knows from previous experience that almost any fungus can be isolated on tomato agar even if other media are more suitable for further growth or fructification. Thirdly, tomato agar is poor in nutrients, thus slowing down the fast growing organisms and giving slow growing fungi a better chance. There is little doubt that tomato agar is particularly suited for use in investigations of this type. The only theoretical disadvantage of tomato agar is that it varies with the quality of the tomatoes used in preparing it. This becomes important in studies of a physiological nature but can hardly be expected to influence the qualitative results of the experiments under discussion. It might be of importance to try a number of other media as well, but interesting results can only be expected in the case of media that are not very suitable for bacteria and yeasts.

Series IX and $\mathrm{X}$ will be discussed next. These two series were collected in the same area. As tomato agar was not used when series IX was analysed, the results offer us a somewhat simplified picture of the soil mycoflora. For this reason, and in order to eliminate the influence of seasonal variations, series IX and $X$ are discussed together. The results are shown in tables V and VI.

One of the most striking features in tables V and VI is the almost complete absence of Phycomycetes. In the dry sandy soils of halophyte zone and grassland this is not surprising, but one would expect a fair amount of Phycomycetes to occur in the mangrove mud where the nutrient level and the moisture content of the soil are both high. Once a colony of Pythium was encountered. To make sure about the frequency of this genus, a few dishes with tapwater-2\% agar were used for samples $X, 1$ and $X, 2$. This special method for the isolation of Pythium gave entirely negative results. From sample X, 1 a fair number of bacteria and yeasts developed, many amoebae were feeding on these, and a few septate mycelia could be seen. From sample X. 2 a fairly high number of diatoms was obtained but no other organisms were observed. This confirms the evidence from the regular analysis that Pythium, and other Oomycetes, are scarcely present in these soils. The use of tapwater agar was then discontinued.

This result is all the more interesting as Oomycetes are among the first and most frequently isolated fungi from marine habitats. Most marine fungi, however, are isolated from amongst seaweeds, or from pieces of organic material usually near the surface of the water, where conditions are aerobic. In mangrove soil, on the other hand, anaerobic conditions prevail. This can be noticed from the presence of a faint smell of $\mathrm{H}_{2} \mathrm{~S}$ in the swamps. It is highly probable that these anaerobic conditions, particularly the presence of some $\mathrm{H}_{2} \mathrm{~S}$, cause the absence of certain fungi from the soil in the swamps, as this substance is highly toxic to fungi. Differences in sensitivity for this poison may very well explain the absence of certain fungi for which no other explanation can be found. The absence of Zygomycetes could 
TABLE $\nabla:$ RESULTS OF ANALYSIS OF SAMPLES FROM SERIES IX ONLY MODIFIED CZAPEK-DOX AGAR WAS USED

\begin{tabular}{|c|c|c|c|c|c|c|c|c|}
\hline \multicolumn{2}{|c|}{ SAMPLE $n ?$} & 1 & 2 & 3 & 4 & 5 & 6 & 7 \\
\hline PHYCOMYCETES & $\begin{array}{l}\text { PAthium } \\
\text { Absidia }\end{array}$ & & & i & & & & \\
\hline ASCOMYCETES & Neocosmospora & 1 & & & & & & \\
\hline $\begin{array}{c}\text { Aspergillus } \\
\text { (groups onty) }\end{array}$ & $\begin{array}{l}\text { glaucus } \\
\text { niger } \\
\text { ochraceus } \\
\text { oryzae } \\
\text { terreus } \\
\text { versicolor }\end{array}$ & $\begin{array}{l}3 \\
1 \\
1\end{array}$ & $\begin{array}{l}\frac{1}{7} \\
1\end{array}$ & $\begin{array}{l}1 \\
4 \\
1 \\
2\end{array}$ & $\begin{array}{l}g \\
i\end{array}$ & 38 & 1 & 2 \\
\hline $\begin{array}{l}\text { Penicillium } \\
\text { (groups only, } \\
\text { in systemakical order) }\end{array}$ & $\begin{array}{l}\text { Frequentans } \\
\text { implicatum } \\
\text { citrinum } \\
\text { chrysogenum } \\
\text { oxalicum } \\
\text { cyclopium } \\
\text { Puniculosum } \\
\text { unidentified }\end{array}$ & $\begin{array}{l}1 \\
1\end{array}$ & $\begin{array}{l}1 \\
3 \\
3 \\
1\end{array}$ & $\begin{array}{c}6 \\
2 \\
10\end{array}$ & $\begin{array}{l}1 \\
2\end{array}$ & 1 & & 1 \\
\hline \multicolumn{2}{|l|}{ BASIDIOMYCETES } & & & & & & & \\
\hline IMPERF & $\begin{array}{l}\text { Fusarium spp. } \\
\text { Trichoderma }\end{array}$ & $\begin{array}{l}10 \\
2\end{array}$ & 2 & $\begin{array}{l}1 \\
3\end{array}$ & $\begin{array}{l}5 \\
3\end{array}$ & 39 & 23 & 86 \\
\hline MPERF ECTI & Haplosporella & & 1 & & & & & \\
\hline -Melanc. & Pestalotia & 3 & 11 & 26 & 36 & 10 & 2 & 3 \\
\hline -Monil-hyaline & Trichothecium & 4 & & & & & & \\
\hline -Monil- -pigmented & $\begin{array}{l}\text { Alternaria } \\
\text { Cladosporium } \\
\text { Curvularia. } \\
\text { Epicoccuma } \\
\text { Helminthosporium } \\
\text { Nigrospora } \\
\text { Papularia } \\
\text { Periconia } \\
\end{array}$ & $\begin{array}{l}4 \\
3 \\
1 \\
\end{array}$ & $\begin{array}{l}6 \\
11 \\
2 \\
4 \\
3 \\
1 \\
\end{array}$ & $\begin{array}{c}2 \\
10 \\
1 \\
11\end{array}$ & $\begin{array}{c}1 \\
9 \\
10\end{array}$ & $\frac{1}{2}$ & $\begin{array}{l}1 \\
1\end{array}$ & $\begin{array}{c}6 \\
i \\
15\end{array}$ \\
\hline $\begin{array}{l}\text { TOTAL - different gener } \\
\text { TOTAL - colonies }\end{array}$ & ra (groups) & $\begin{array}{l}13 \\
35\end{array}$ & $\begin{array}{l}18 \\
58\end{array}$ & $\begin{array}{l}16 \\
83\end{array}$ & $\begin{array}{l}12 \\
79\end{array}$ & $\begin{array}{l}6 \\
91\end{array}$ & $\begin{array}{l}5 \\
28\end{array}$ & $\begin{array}{c}8 \\
115\end{array}$ \\
\hline $\begin{array}{l}\text { STERILE MYCELIA } \\
\text { UNIDENTIFIED }\end{array}$ & & 4 & 1 & $\begin{array}{l}2 \\
2\end{array}$ & 1 & 2 & 1 & \\
\hline
\end{tabular}

hardly be explained otherwise. The mangrove soil is rich in organic material; it contains a fair amount of ammonium- and organic nitrogen, for which fungi from this group show a preference; its moisture content is always high.

Ascomycetes, apart from Aspergillus and Penicillium, are not common in any of the samples, but their number may be higher than appears from the tables as part of the sterile mycelia may represent Ascomycetes.

Basidiomycetes are conspicuous by their absence. No fruiting bodies of Basidiomycetes have been observed in or near the swamps although 
TABLE $\nabla T$ : RESULTS OF ANALYSIS OF SAMPLES FROM SERIES $\mathbf{x}$ BOTH MEDIA WERE USED AND THE RESULTS OBTAINED ON EACH ARE LISTED SEPARATELY.

$$
C_{\mathbf{2}} \cdot \mathbf{D}=\text { modified } C_{\text {zapek }} \cdot \text { Dox agar }
$$

$T=$ tomato decoction agar

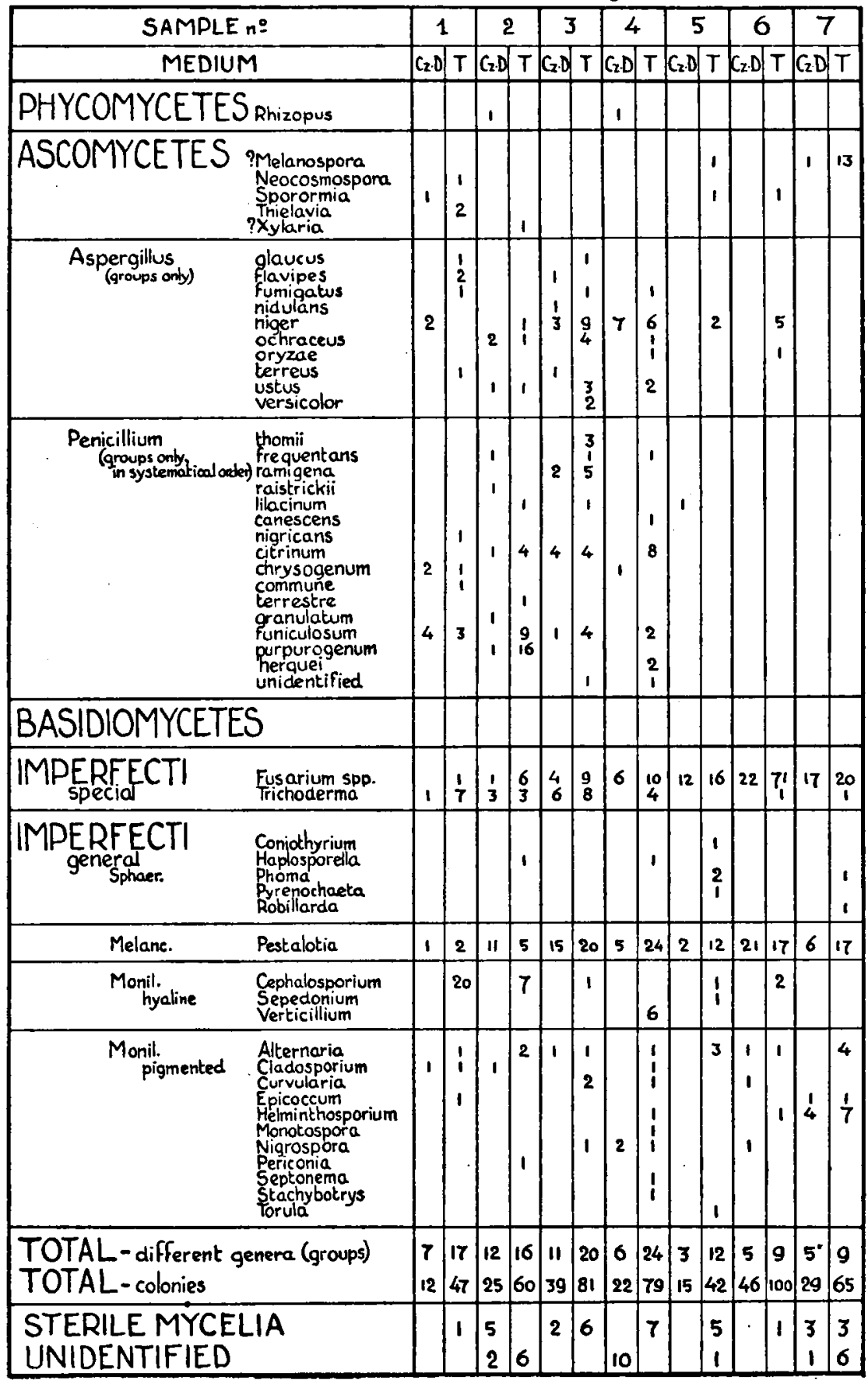


they are regularly encountered in the wooded parts of the inland vegetation. It is possible that in the area under investigation conditions are not suitable for this group of fungi, either by the anaerobic conditions and the absence of the right kind of organic material in the swamp, or by the rather poor and often arid conditions in the sandy soil of halophyte zone and grassland.

A study of the distribution of species of the genera Aspergillus and Penicillium is very interesting. As has been mentioned before, members of the Aspergillus glaucus group are not common, but of interest, as they are restricted to the mangrove soil (samples 1-4). This can be explained by the high nutrient level in the swamp and particularly by the fact that these species prefer a medium with a high osmotic value and thus can compete more easily in the salty soil of the swamps. Species of the $A$. niger group are more common than any other Aspergilli and they are the only ones that do occur regularly in the samples from outside the swamp. There are indications that there is some differentiation as far as species in this group are concerned: $A$. awamori is more frequent in the mangrove mud than in the sandy soils. The remaining groups in the genus are fairly well represented in the mangrove soil but from the sand only an occasional colony was isolated.

The genus Penicillium presents a picture fairly similar to that of Aspergillus. A great variety of species is present in samples 1 to 4 , but outside the swamp Penicillium is found only occasionally. The best represented groups are the $P$. citrinum group and the $P$. funiculosum group. Members from this last group are not common in samples from series IX, but their importance in series $X$ is evident, and in series XII they were very frequent.

It is of interest to see in how far the results from series IX and X are in agreement with the findings from series XII. A great number of both colonies and species of Aspergillus occurs in samples XII, 1, 2, 3, corresponding to IX, 3 and X, 3. In samples XII, 4, 5 and 6 , there is more Aspergillus than in samples IX, 7 and X, 7, but it appears from the sampling notes that the last samples in series XII were taken a little further inland than those from series IX and X and this may well explain the difference (see also the discussion of series XI). Essentially the same applies to the findings on Penicillium.

The distribution of Aspergillus and Penicillium, as discussed above, may be caused by several factors. As can be seen from the soil analysis, the soil in the mangrove swamp is rich in both carbon and nitrogen. The organic material is of a different nature from that in the zones outside the swamp in that most of it is carried in by the sea at high tides. Consequently there will be less cellulose and probably more simple carbohydrates in this soil than in those of halophyte zone and grassland. In Garrett's classification of soil fungi into ecological groups, Aspergillus and Penicillium figure among the saprophytic sugar fungi. This indicates their preference for simple organic compounds and so they are among the first fungi to get established on newly available nutrient sources. As these requirements are best fulfilled in 
the soil of the mangrove swamp it is there that the greatest number of these fungi can be found. The only group of Aspergilli that seems to be associated with decomposition of cellulose, the $A$. niger group, is the only group that is well represented outside the swamp area.

From the imperfect fungi the genera Fusarium and Trichoderma have been singled out. Trichoderma is practically absent from the soil in the halophyte zone, but present elsewhere. Fusarium offers an interesting picture by its increase in numbers beyond the swamp area. It is not restricted to any particular soil and one gets the impression that the amount of Fusarium is mainly dependent on the competition this fungus gets from other fungi that are more sensitive to their surroundings. Fusarium can easily survive under the arid conditions prevailing in the sandy soils outside the swamps as it is able to produce chlamydospores. These can be formed under the influence ot adverse external conditions (PARK, 1954) and so help the fungus to survive until enough moisture and nutrients have become available for further growth. It is likely that many of the Fusarium colonies, obtained from the poorest soils, were derived from chlamydospores. A further study of this genus may give valuable information.

Little can be said about the Sphaeropsidales as they are comparatively few. Among the Melanconiales the genus Pestalotia stands out. Members of this genus are usually regarded as typical plant parasites, but the abundance of Pestalotia in all samples collected in area $\mathrm{I}$, including all samples from series XII, indicates its importance as a constituent of the soil mycoflora of this area. RrTaHre (1957) mentions the genus as able to live under saline conditions. The results given in tables IV, V and VI, show clearly that the fungus is equally abundant in the mangrove soil and in the sand around the swamps. In several samples it is the dominant genus. Not enough is known about this genus to explain its behaviour.

In the Moniliales one of the main features shown is the small number of hyaline fungi, whereas pigmented forms are fairly common in all samples. This adds to the evidence from other sources, that a separation based on the presence or absence of dark pigments in some fungi is not quite as artificial as is sometimes assumed. The genus Helminthosporium, many species of which are parasitic on grasses, is more common in the grassland samples than elsewhere. Other genera occur in small numbers and no conclusions can be drawn from their distribution. From the results of series XII we might conclude that the dematiaceous imperfect fungi are more abundant in the surface soil, but most genera are present in the subsurface layer as well.

The overall pattern of fungus distribution in Area I indicates a strong positive correlation between the amount of organic material and the number of genera present. There is no such correlation between amount of organic material and number of colonies, but this is due to the fact that bacteria and yeasts have not been taken into account and these dominate the microflora of the mangrove soil, whereas they are of far less importance in the sandy soils.

The results of series $\mathrm{XI}$ are somewhat different from those of the 
TABLEVIT:RESULTS OF ANALYSIS OF SAMPLES FROM SERIES XT BOTH MEDIA WERE USED AND THE RESULTS OBTAINED ON EACH ARE LISTED SEPARATELY

$C z \cdot D=$ modified Czapek $\cdot$ Dox agar $T=$ tomato decoction agar

\begin{tabular}{|c|c|c|c|c|c|c|c|c|c|c|c|c|}
\hline \multicolumn{2}{|c|}{ SAMPLE $n g$} & \multicolumn{2}{|c|}{1} & \multicolumn{2}{|c|}{2} & \multicolumn{2}{|c|}{3} & 4 & \multicolumn{2}{|r|}{5} & \multicolumn{2}{|c|}{6} \\
\hline MEDIUI & & $c_{2} \cdot D$ & & $C_{2} \cdot \mathrm{D}$ & $T$ & 20 & $T C$ & \begin{tabular}{l|l}
$D$ & $T$ \\
\end{tabular} & & D T & & $T$ \\
\hline PHYCOMYCETES & $\begin{array}{l}\text { Absidia } \\
\text { Cunninghamella }\end{array}$ & & & 1 & & & & & & & & $\infty$ \\
\hline \multicolumn{13}{|l|}{ ASCOMYCETES } \\
\hline $\begin{array}{c}\text { Aspergillus } \\
\text { (groups only) }\end{array}$ & $\begin{array}{l}\text { glaucus } \\
\text { fumigatus } \\
\text { niger } \\
\text { ochraceus } \\
\text { oryzae } \\
\text { terreus } \\
\text { versicolor }\end{array}$ & \begin{tabular}{|l}
8 \\
2 \\
2
\end{tabular} & & 7 & I & 8 & $\begin{array}{l}13 \\
4 \\
1\end{array}$ & $6 \mid 6$ & 1 & $\begin{array}{l}6 \\
2 \\
2\end{array}$ & & $\begin{array}{l}947 \\
\infty \\
1\end{array} \mid$ \\
\hline 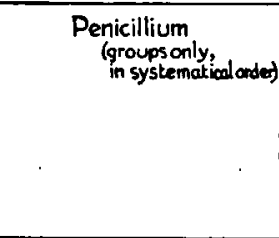 & 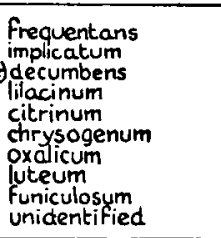 & 1 & 2 & 1 & 3 & 2 & 1 & $3 \mid 3$ & & 1 & $?$ & \pm 40 \\
\hline \multicolumn{13}{|c|}{ BASIDIOMYCETES } \\
\hline IMPERFECTI & $\begin{array}{l}\text { Fusarium spp. } \\
\text { Trichoderma }\end{array}$ & & 3 & 2 & $\begin{array}{l}5 \\
4\end{array}$ & 2 & 3 & 3 & 38 & 87 & $\frac{1}{3}$ & $>6$ \\
\hline $\begin{array}{l}\text { IMPERFECTI } \\
\text { general-Sphoer. }\end{array}$ & (?Micro)diplodia & 1 & & 1 & & & & & & & & \\
\hline - Melane. & $\begin{array}{l}\text { Colletotrichum } \\
\text { Pestalotia }\end{array}$ & 1 & & & 2 & 1 & ! & \begin{tabular}{l|l}
2 & 1
\end{tabular} & & 2 & 1 & \\
\hline - Monil & $\begin{array}{l}\text { Botrytis } \\
\text { Cepholisporium } \\
\text { Paecilomyces }\end{array}$ & & $\begin{array}{l}1 \\
2\end{array}$ & & 2 & & i & ' & I & & & \\
\hline $\begin{array}{l}\text { - Monil. } \\
\text { pigmented }\end{array}$ & 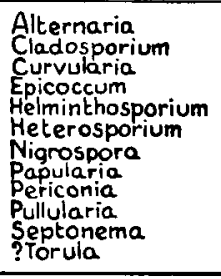 & 4 & $\frac{1}{2}$ & 1 & $\begin{array}{l}2 \\
1 \\
3 \\
1\end{array}$ & $\begin{array}{l}4 \\
1\end{array}$ & $\begin{array}{l}2 \\
1 \\
1\end{array}$ & 1 & 2 & $\begin{array}{l}15 \\
27 \\
2 \\
2 \\
1 \\
5 \\
1 \\
1\end{array}$ & & 1 \\
\hline $\begin{array}{l}\text { TOTAL-different } \\
\text { TOTAL-colonies }\end{array}$ & genera (groups) & \begin{tabular}{|c|}
7 \\
18 \\
\end{tabular} & $\begin{array}{l}16 \\
21\end{array}$ & \begin{tabular}{c|c}
7 & 1 \\
14 & 4
\end{tabular} & $\begin{array}{l}18 \\
42\end{array}$ & $\begin{array}{c}7 \\
19\end{array}$ & 17 & \begin{tabular}{l|l}
7 & 9 \\
7 & 2
\end{tabular} & & 16 & & $\left|\begin{array}{l}>9 \\
\infty\end{array}\right|$ \\
\hline $\begin{array}{l}\text { STERILE MYCE } \\
\text { UNIDENTIFIE }\end{array}$ & DLIA & \begin{tabular}{|l|}
3 \\
2 \\
\end{tabular} & $\begin{array}{l}4 \\
1\end{array}$ & $\begin{array}{l}1 \\
1\end{array}$ & 5 & 1 & $\begin{array}{l}4 \\
3\end{array}$ & $\begin{array}{l}3 \\
1\end{array}$ & 3 & \begin{tabular}{l|}
2 \\
3
\end{tabular} & & Dral \\
\hline
\end{tabular}


previous series but do not lead to any different conclusions. Chemical det ails of the soil in area II are not available but superficial examination clearly shows the more sandy nature of the soil in the Avicennia swamp. The last sample of the series was taken further inland than those of series IX and X. In the mixed grassland, from which it was obtained, the soil is covered with a fair amount of plant debris.

A detailed analysis of the results of series XI is made difficult by the abundance of Absidia in sample 6. This fungus had overgrown the plates, thus making observation of other fungi difficult and their isolation impossible. Nevertheless the results of sample 6 are important in several respects.

The results of series XI are given in table VII and should be compared with fig. 2, in which the location of the sampling spots in relation to the vegetation is indicated.

The major feature in the distribution of Phycomycetes in this area has already been mentioned. They are almost absent except in sample 6 where a species of Absidia dominates the mycoflora. In the soil of this sample conditions are aerobic and the abundance of plant debris makes it quite suitable for the so called "Saprophytic sugar fungi" among which the Zygomycetes are placed (GARRETT, 1951). Other "sugar fungi" like Aspergillus and Penicillium show the same increase in numbers in sample 6 as compared with the other samples. The distribution of these two genera in samples 1 to 3 is different from that in the corresponding part of area I: they are less frequent in the comparatively poor soil of the Avicennia swamp of area II than in the rich mud of the mixed mangrove swamp of area $I$.

Basidiomycetes are absent in this series. The distribution of Aspergillus and Penicillium has just been discussed. They are the only Ascomycetes present.

The genus Trichoderma occurs in small numbers in most samples but is more frequent in sample 6 , undoubtedly because of the higher amount of plant debris in this soil. Fusarium occurs in all samples but shows an unexpected peak in sample 5. In this sample it is so abundant that the total number of colonies is very much higher than in any of the other samples. This excessive abundance is difficult to explain.

Pestalotia is comparatively unimportant in area II. Hyaline Moniliales are few, as in area I. Dematiaceous members of the order are present in small numbers but with quite a variety of genera. A sudden peak in numbers is reached in sample 5. This indicates that for certain fungi, including Fusarium, conditions in this part of the area seem to be particularly favourable. Sample 6 is poor in imperfect fungi but they may have escaped observation under the dense cover of Absidia.

The above discussion of the results of series XI shows that, where differences do occur, as compared with series IX and X, they can be easily explained by the different soil conditions. Only two features remain unexplained: the difference between the two areas in the amount of Pestalotia and the peak in fungal numbers in sample XI, 5. Sample XI, 6 is important by showing an increase in numbers and 
a greater variety of fungi to be present in the soils further away from the swamp, where more plant debris is available for decomposition. Here Zygomycetes are as abundant as in any soil with a sufficiently high nutrient level.

To conclude this discussion the results outlined and explained above will be compared with some of the results obtained by other workers under more or less similar conditions. As appears from the literature review, a positive correlation between total amount of carbon and the number of fungi has been found in several investigations. In the present investigation this correlation seems to be absent, but it would probably have been evident for the total number of microorganisms if bacteria and yeasts had been taken into account. On the other hand a definite correlation is shown between total amount of carbon and variety of fungus flora. There is a possibility of other nutrient factors being of importance in this respect. The nitrogen supply, particularly the amount of organic nitrogen, seems to be correlated with the number of genera and species present. In the grassland there is a fairly large but rather uniform fungus population and here more nitrogen is present in the form of nitrate than elsewhere.

Another feature shown in several investigations is that the microflora varies with the surface vegetation. These two floras influence one another and both are influenced by soil conditions, etc. In the present investigation the influence of the soil conditions on the fungus population can be assumed to be more important than that of the higher plants as even in the grassland the vegetation is rather open (except for sample $\mathrm{XI}, 6)$.

The investigation of MontÉguT (1956) in the coastal area of Gascogne shows Phycomycetes to be rare in coastal area's. This is explained by the alternating wet and dry conditions. In the mangrove swamps the soil is sufficiently wet and the rarity of Phycomycetes must thus be caused by some other factor. In both cases it is possible that the salt content of the soil makes conditions unsuitable for Zygomycetes as these organisms show a tendency to grow abnormally and fructify poorly in concentrated media. This explanation, however, does not hold for many Oomycetes as they are regularly found growing in marine habitats. In this case the anaerobic conditions in the swamp offer a suitable explanation.

One of the results of Nrcot (1956) is confirmed by the work on Inhaca soils, namely the absence of Trichoderma under highly saline conditions. In the swamps, with their constant salinity level, this genus is present in small amounts, but it is absent from the halophyte zone where the regularly occurring dry conditions will result in a relatively higher salinity even if the total amount of sodium chloride is lower than in the intertidal zone. In the grassland, where little sodium chloride is present the fungus reappears. A difference in behaviour between the genera Aspergillus and Penicillium, as found by Nicot, definitely does not occur in the soils of Inhaca where the numbers of species and of colonies in these genera increase and decrease more or less simultaneously. 


\section{SUMMARY}

The horizontal distribution of fungi in and around two mangrove swamps on the island of Inhaca (Portuguese East Africa) was investigated by a direct inoculation method. Some information on the physical and chemical properties of the soils was obtained to find correlations between nutrient levels, etc., and the nature of the fungus population. There is a definite positive correlation between the amount of carbon and the variety in the fungus flora, and it is suspected that the nature of the nitrogen source is important as well. Phycomycetes are almost absent but were found in great number in one sample taken somewhat further inland. Ascomycetes are rare except for Aspergillus and Penicillium, and Basidiomycetes are entirely absent. Aspergillus and Penicillium are present in great variety in the swamps but relatively few species are found in the sandy soils. Fusarium is common and present in great numbers in the poorest soils. In one of the two swamps the genus Pestalotia is abundant. Few hyaline and many dark members of the Moniliales can be found in most parts of the investigated area's. The surface vegetation shows the same amount of variation as the fungus population, but there are indications that both are influenced more or less independently by the variation of soil conditions.

\section{AGKNOWLEDGEMENTS}

The author is very grateful to the head of the Department of Zoology of the Witwatersrand University and to the Portuguese authorities concerned for the opportunity to take part in a number of excursions to the island of Inhaca. He wants to convey his sincere thanks to Professor N. P. Badenhuizen, head of the Department of Botany of the Witwatersrand University who stimulated him to undertake this research work and helped with constructive criticism.

\section{REFERENCES}

Atkinson, R. G. and J. B. Robinson. 1955. Can. Jour. Bot. 33: 281.

BRown, J. C. 1958. Trans. Brit. mycol. Soc. 41: 81.

Chesters, C. G. G. and R. H. Thornton. 1956. Trans. Brit. mycol. Soc. 39: 301. Enghusen, H. 1956. Zbl. Bakt. Abt. 2, 109: 157

Evans, E. and D. Gotrumb. 1955. Soil Science 80: 295.

Garretr, S. D. 1951. New Phytol. 50: 149. 1955. Trans. Brit. mycol. Soc. 38: 1. 1956. Biology of root infecting fungi, Cambridge.

Gilman, J. C. 1957. A manual of soil fungi, 2 nd ed., Iowa.

Gulllemat, J. and J. MonTÉGUT. 1956. Ann. Inst. Rech. agron. Sér. G 7, 3: 471.

MACNAE, W. and M. KALK. 1958. A natural history of Inhaca island, Mocambique; Johannesburg.

Mc Lennan, E. I. and S. C. Ducker. 1954. Austr. Jour. Bot. 2: 220. and 1 1957. Austr. Jour. Bot. 5: 36.

Menon, S. K. and L. E. Williams. 1957. Phytopath. 47: 559.

Montégut, M. J. 1956. C. R. Acad. Sci. Paris 243: 1144.

Nrcholss, V. O. 1956. Trans. Brit. mycol. Soc. 39: 233.

Nicot, J. 1956. C. R. Acad. Sci. Paris 243: 820.

OrPuRT, P. A. and J. T. Gurtis. 1957. Ecology 38: 628.

PARK, D. 1954. Nature $173 \mathrm{n}^{\circ}$ 4401: 454.

1955. Trans. Brit. mycol. Soc. 38: 130.

- 1957. Trans. Brit. mycol. Soc. 40: 283.

1957. Trans. Brit. mycol. Soc. 40: 358.

RrTchIE, D. 1957. Am. Jour. Bot. 44: 870.

Rose, R. E. and J. G. Miller. 1954. J. Gen. Microbiol. 10: 1.

Saksena, S. B. 1955. J. Indian bot. Soc. 34: 262.

Stevenson, I. L. and F. E. Chase. 1957. Can. Jour. Microbiol. 3: 351.

Stolk, A. C. 1955. Trans. Brit. mycol. Soc. 38: 419.

THORNTON, R. H. 1952. Research 5: 190. 1956. Nature $177 \mathrm{n}^{\circ}$ 4501: 230. 1956. Trans. Brit. mycol. Soc. 39: 485.

WAID, J. S. 1957. Trans. Brit. mycol. Soc. 40: 391. 
Warcup, J. H. 1951. Trans. Brit. mycol. Soc. 34: 376.

1955. Trans. Brit. mycol. Soc. 38: 298.

1957. Trans. Brit. mycol. Soc. 40: 237.

Webley, D. M., D. J. Eastwood and C. H. Gimingham. 1952. Journ. Ecology 40: 168.

WEBster, J. 1956. Journ. Ecology 44: 517.

1957. Journ. Ecology 45: 1.

WrIGHT, J. M. 1956. Ann. appl. Biol. 44: 461.

and J. F. Grove. 1957. Ann. appl. Biol. 45: 36. 